\title{
Removal of heavy metal from synthetic wastewater using Rice husk and Groundnut shell as adsorbents
}

\author{
Prabha R.T. ${ }^{1}$, Dr. Udayashankara T.H. ${ }^{2}$ \\ I'M.tech student, Department of Environmental Engineering, Sri Jayachamarajendra College of Engineering, \\ Mysore, Karnataka, India) \\ ${ }^{2}$ (Proffesor, Department of Environmental Engineering, Sri Jayachamarajendra College of Engineering, \\ Mysore, Karnataka, India)
}

\begin{abstract}
The industrial activities and technology development lead to a significant release of important quantities of heavy metal ions to the environment. Batch experiments were conducted to know the influence of various parameters of adsorption on removal of lead metal ions by agricultural byproducts (Groundnut shell, Rice husk and combined adsorbents). It has been found that the percentage of adsorption increases with increase in $p H$ (in acidic range) and decreases with the increase in metal ions concentration. Equilibrium time required for the adsorption of lead by agricultural byproducts was found to be 2 hrs. The obtained results showed that the adsorption of lead by rice husk and Groundnut shell are of second order reaction.
\end{abstract}

Keywords: Adsorption, Agricultural byproducts, Heavy metals, Isotherms, Kinetics.

\section{Introduction}

Water pollution due to the disposal of heavy metals continues to be a great concern worldwide. Heavy metals pollution occurs in much industrial wastewater such as that produced by metal plating facilities, mining operations, battery manufacturing processes, the production of paints and pigments, and the ceramic and glass industries. Whenever toxic heavy metals are exposed to the natural eco-system, accumulation of metal ions in human bodies will occur through either direct intake or food chains. Even a very small amount can cause severe physiological or neurological damage to the human body. Therefore, heavy metals should be prevented from reaching the natural environment [1].

There are various methods of removing heavy metal ions, and they include chemical precipitation, membrane process, ion exchange, solvent extraction, electrodialysis, and reverse osmosis. These methods are non economical and have many disadvantages such as incomplete metal removal, high reagent and energy consumption, and generation of toxic sludge or other waste products that require disposal or treatment [2].

Biosorption is a process that utilizes low-cost biosorbent to sequester toxic heavy metals. Biosorption has distinct advantages over the conventional methods, which include reusability of biomaterial, low operating cost, selectivity for specific metal, short operation time and no chemical sludge. In the recent years many biosorbent materials of agricultural based have been utilized for heavy metal biosorption. These include: coconut husk and shell, sea weeds, bagasse ash, hazelnut shell, peanut hull, tree fern, black gram husk, maize leaf, maize, sun flower waste, coffee beans, Ficus religiosa leaves, wheat bran, almond shell, tea waste [3].

\subsection{LEAD}

Lead $(\mathrm{Pb})$ is considered as one of the priority metals from the point of view of potential health hazards to human, and it is listed by the Environmental Protection Agency (EPA) as one of 129 priority pollutants [2]. Lead as a pollutant is a major concern as it has been used as one of the raw materials for battery manufacturing, printing, pigments, fuels, photographic materials and explosive manufacturing. The presence of lead in drinking water even at low concentration may cause diseases such as anemia, encephalopathy, hepatitis and nephritic syndrome [4].

Severe lead poisoning can cause encephalopathy with permanent damage, while moderate lead poisoning result in neurobehavioral and intelligent deficit. Lead poisoning in humans causes severe damage to kidney, nervous system, reproductive system, liver and brain. According to the United States Environmental Protection Agency (USEPA) the maximum permissible limits in wastewater and potable water are $0.1 \mathrm{mg} / \mathrm{L}$ and $0.015 \mathrm{mg} / \mathrm{L}$ for lead (II) [3]. 


\subsection{Adsorbent preparation}

\section{Materials And Methadology}

Rice husk and Groundnut shell were ground separately and sieved to obtain particle size of $0.6 \mathrm{~mm}$. The sieved adsorbents were washed with distilled water several times to remove dust and kept in an oven at $65^{\circ} \mathrm{C}$ for $24 \mathrm{~h}$ to reduce the moisture content. Then these adsorbents were used for batch experiments.

\subsection{Adsorbate}

Stock solutions of lead (II) were prepared by dissolving $1.59 \mathrm{~g}$ of lead nitrate in $1000 \mathrm{ml}$ distilled water. Different initial concentrations of metal ions were prepared by diluting the stock solutions. The $\mathrm{pH}$ was maintained using $0.1 \mathrm{~N} \mathrm{HCl}$ and $0.1 \mathrm{NaOH}$ solutions.

\subsection{Batch experiments}

The experiments were carried out under constant shaking of $100 \mathrm{ml}$ of simulated solutions in conical flasks in heavy rotatory shaking apparatus. Samples were withdrawn after a definite time interval and filtered through Whatman No. 41 filter paper and then measured in ICP. The amount of metal ions adsorbed by adsorbent is calculated using the following equation:

Where,

$$
\mathrm{q}_{\mathrm{e}}=(\mathrm{Co}-\mathrm{Ce}) \mathrm{V} / \mathrm{M}
$$

$\mathrm{Co}=$ Initial concentrations of the metal ion in solution $(\mathrm{mg} / \mathrm{L})$

$\mathrm{Ce}=$ Final concentrations of metal ion solution $(\mathrm{mg} / \mathrm{L})$

$\mathrm{V}=$ solution volume $(\mathrm{L})$ and

$\mathrm{M}=$ mass of the sorbent $(\mathrm{g})$

\section{Results And Discussions}

\subsection{General}

Adsorption studies have been conducted for the removal of lead from aqueous solution. Batch experiments were carried out under different $\mathrm{pH}$, time, initial concentration of metal ions and adsorbent doses. The results of the above study are presented in the following section.

\subsection{Effect of $\mathrm{pH}$}

The $\mathrm{pH}$ of solution is significantly influence the removal of heavy metals hence it is an important condition for adsorption of lead metal ions. With the contact time of $2 \mathrm{~h}$ batch experiments were carried out at different $\mathrm{pH}$ values (3-10) with $30 \mathrm{mg} / \mathrm{L}$ of lead. Fig. land Fig. 2 reveals that adsorption capacity of lead metal ions. At $\mathrm{pH} 6,1 \mathrm{~g}$ of Rice husk was able to give lead removal efficiency of $93.78 \%$ and at $\mathrm{pH} 5$ lead removal efficiency was $97.48 \%$ using $1 \mathrm{~g}$ of Groundnut shell.

At low $\mathrm{pH}$, high concentrations of $\mathrm{H}^{+}$ions were present in solution that competes for vacant adsorption sites of adsorbent. This phenomenon could be confirmed by the observation of sharp increase in the final solution $\mathrm{pH}$ of those having low initial $\mathrm{pH}$ values. For each hydrolysable metal ion, there was a critical $\mathrm{pH}$ range where the metal uptake efficiency increased from a very low level to maximum value. Decreasing trend in uptake was observed above $\mathrm{pH} 8$ due to formation of soluble hydroxyl complexes [5].

\subsection{Effect of contact time}

In the present study, effects of contact time (15 - $165 \mathrm{~min})$ on the removal of lead metal ions have been carried out with initial concentration of $30 \mathrm{mg} / \mathrm{L}$ at $\mathrm{pH}$ 7. The maximum uptake of lead was at $2 \mathrm{~h}$ using Rice husk and Groundnut shell as adsorbents. After $2 \mathrm{~h}$, the $\%$ removal was negligible hence all experiments were carried out at equilibrium time of $2 \mathrm{~h}$.

As can be seen from the Fig. 3and Fig. 4, the biosorption process took place in two stages. The first stage was rapid, where about $89.86 \%$ biosorption was completed by Rice husk and $91.56 \%$ biosorption was completed by Groundnut shell within first $15 \mathrm{~min}$. The second stage represented a slower progressive biosorption. The rapid initial biosorption may be attributed to the accumulation of metals on to the surface of biosorbent, due to its large surface area. With the progressive occupation of these sites, process became slower in the second stage [3].

\subsection{Effect of initial concentration of metal ions}

The adsorption experiments were carried out with metal ion concentrations of 20, 40, 60, $80,100,120,140$ and $160 \mathrm{mg} / \mathrm{L}$ at $\mathrm{pH} 7$ using $1 \mathrm{~g}$ of Rice husk and Groundnut shell. The effect of initial concentration of lead is shown in Fig. 5 and Fig. 6 for Rice husk and Groundnut shell respectively. Results from these plots indicate that lead removal efficiency decreases from $99.37 \%$ to $39.70 \%$ for Rice husk and from 
$99.18 \%$ to $97.17 \%$ for groundnut shell as the initial concentration of lead increased from $20 \mathrm{mg} / \mathrm{L}$ to $160 \mathrm{mg} / \mathrm{L}$. Fig. 9 shows that removal efficiency by combined adsorbents (Rice husk and Groundnut shell) decreases from $93.90 \%$ to $71.50 \%$ as the initial concentration of lead increased from $200 \mathrm{mg} / \mathrm{L}$ to $450 \mathrm{mg} / \mathrm{L}$.

At low metal ion loads, adsorption involved the high energy sites. Under these conditions, the ratio of number of moles of metal ion to the available adsorption sites was low, and therefore, the amount adsorbed per unit mass increased slowly. With an increase in metal ion load, the higher energy sites would be rapidly saturated and the metal ions would gradually occupy the lower energy sites, resulting in a continuous increase in the amount adsorbed per unit mass [6].

\subsection{Effect of adsorbent dose}

The effect of adsorbent doses of Rice husk, Groundnut shell ranging from $2-9 \mathrm{~g} / \mathrm{L}$ and combined adsorbents(Rice husk and Groundnut shell) ranging from $2-7 \mathrm{~g} / \mathrm{L}$ on lead removal are shown in Fig. 7 and Fig. 8 Fig. 10 respectively. The results indicate that the percentage removal of lead increases as the adsorbent dose increases by giving removal efficiency from $93.53 \%$ to $97.11 \%$ for rice husk, from $97.82 \%$ to $98.90 \%$ for Groundnut shell and from $95.58 \%$ to $97.02 \%$ for combined adsorbents (Rice husk and Groundnut shell).

The removal efficiency and specific uptake of metals depend on type and quantity of the biosorbent. The increase in percentage removal of lead with increase in adsorbent dose was due to the availability of more and more adsorbent surfaces for the solutes to adsorb.

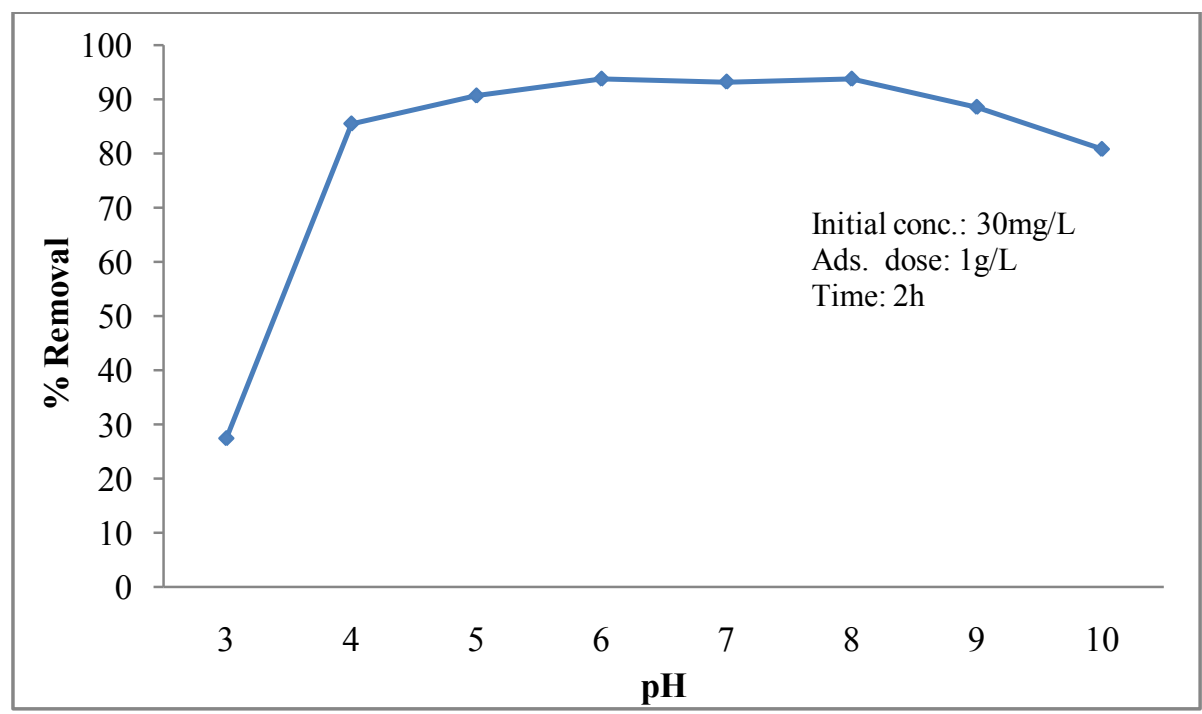

Fig. 1: Percentage removal of lead by Rice husk at different $\mathrm{pH}$ values

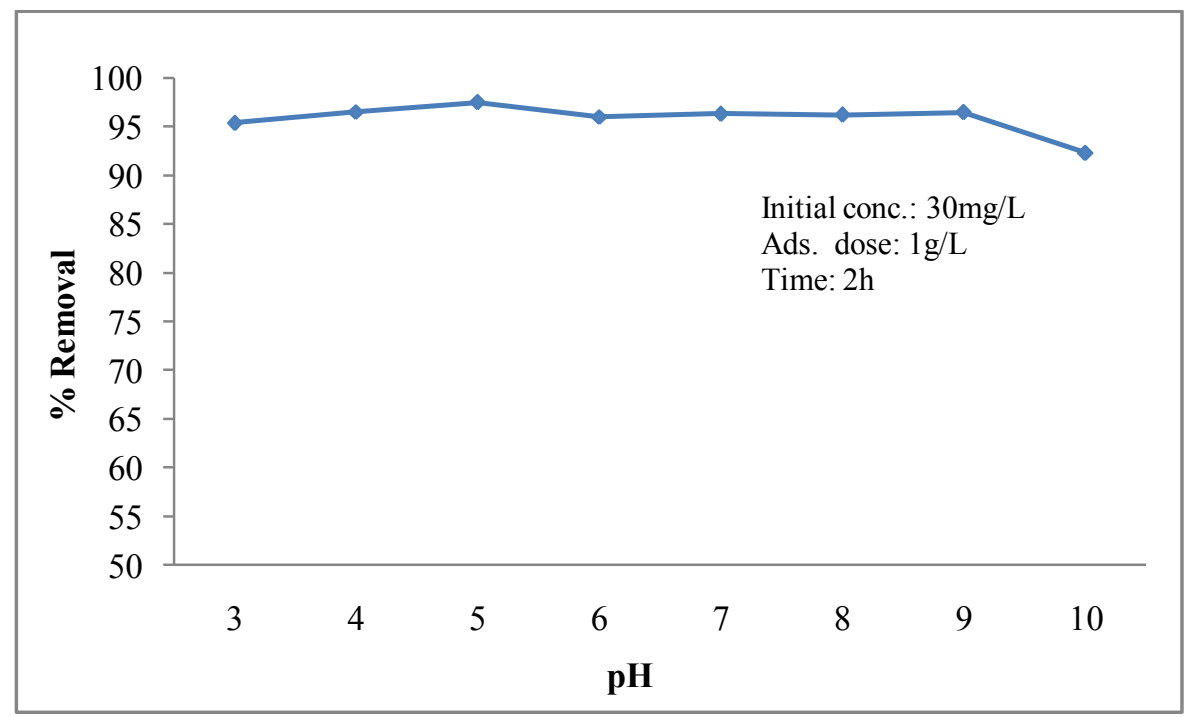

Fig. 2: Percentage removal of lead by Groundnut shell at different $\mathrm{pH}$ values 


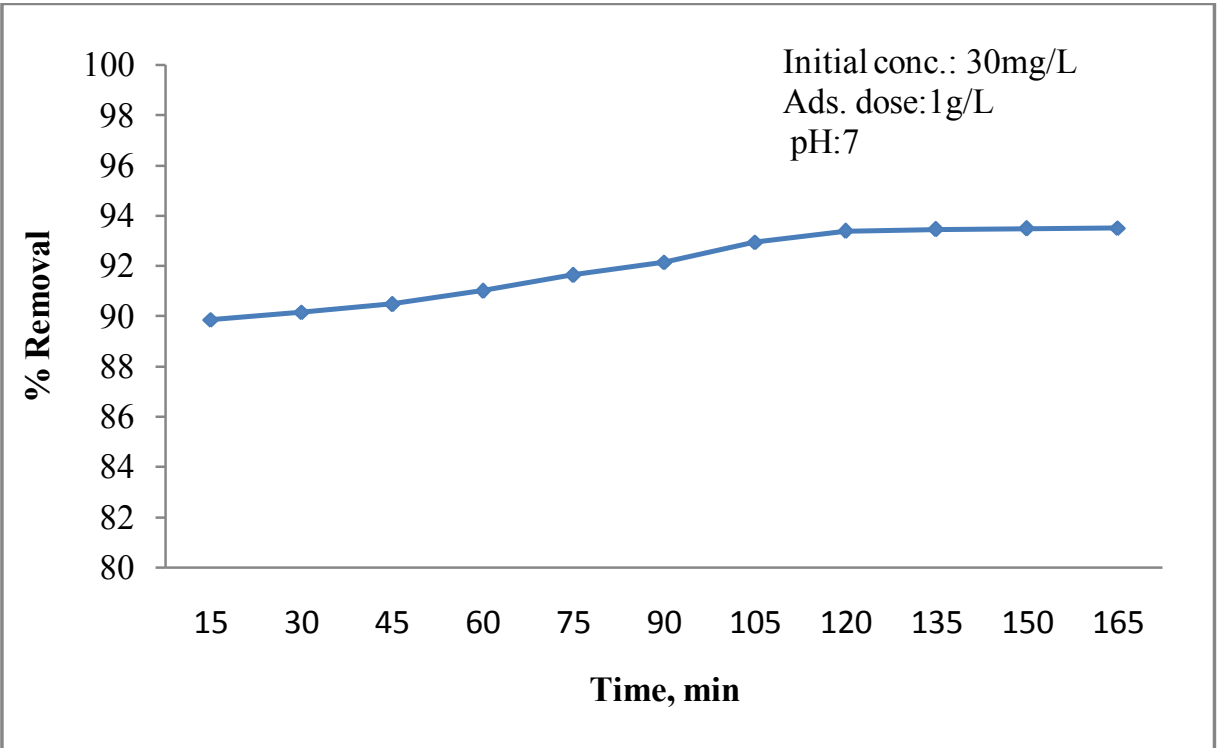

Fig. 3: Effect of contact time on lead removal by Rice husk

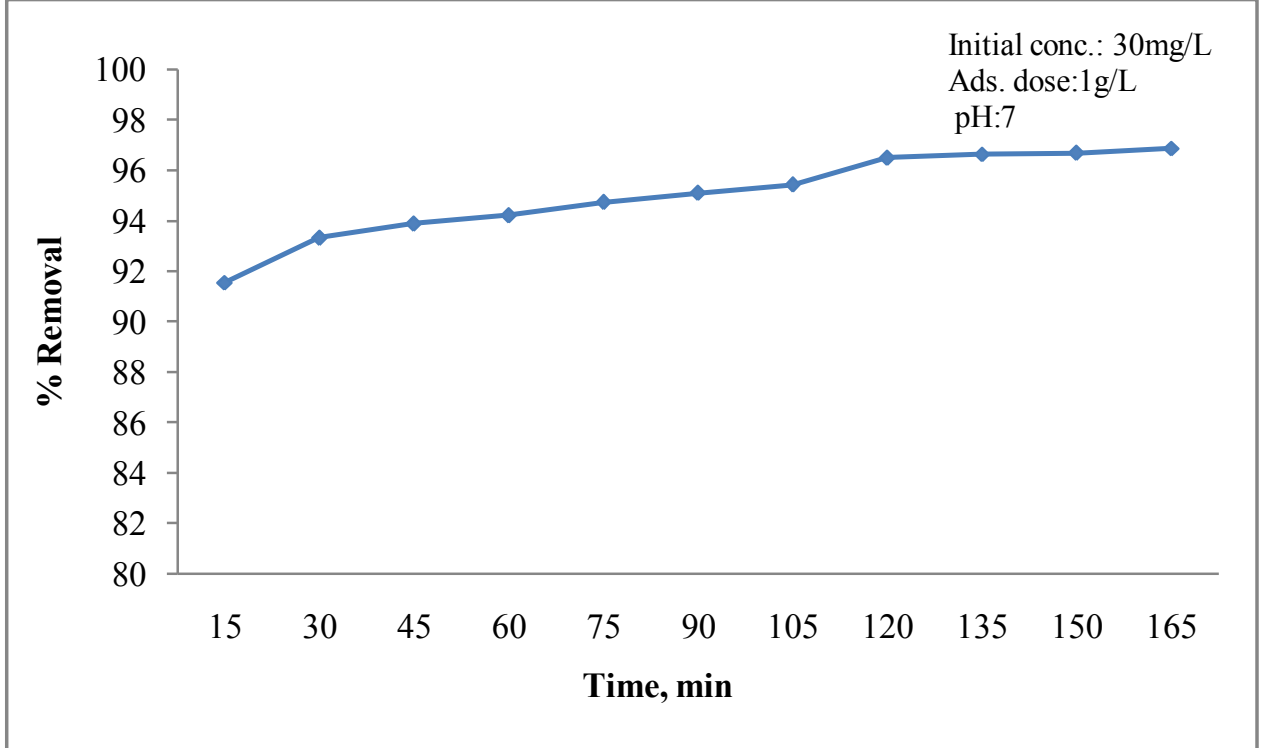

Fig. 4: Effect of contact time on lead removal by Groundnut shell

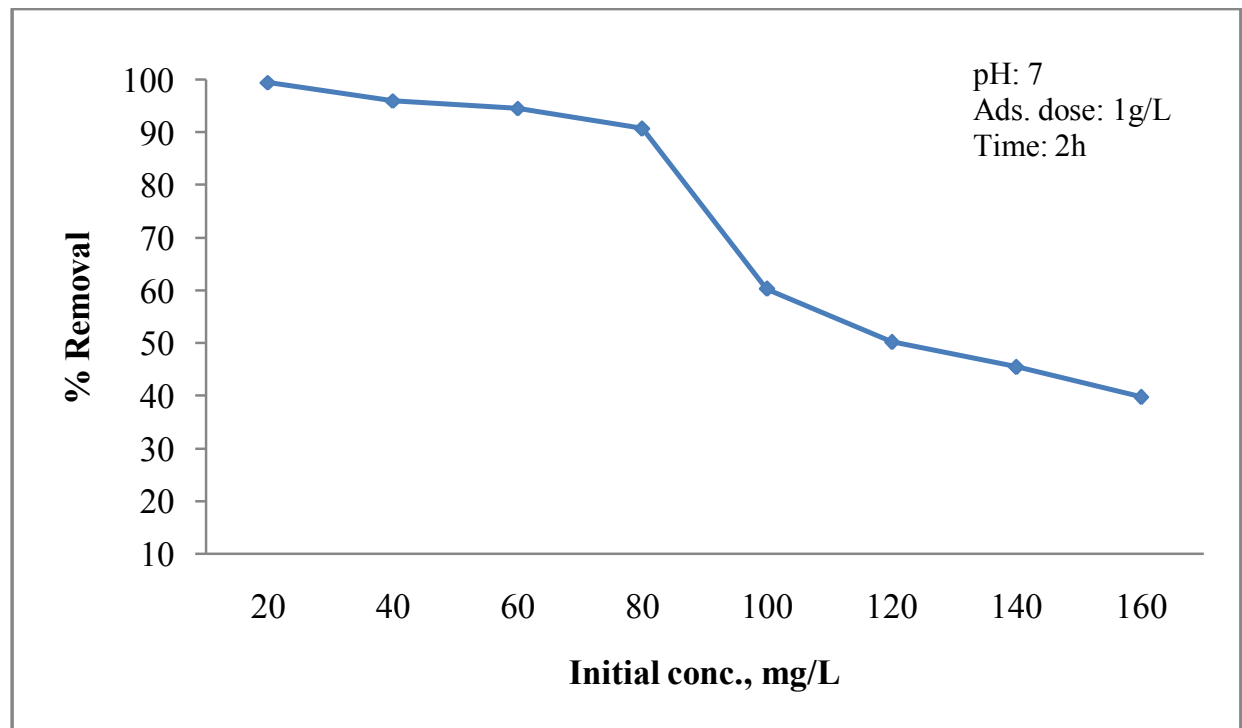

Fig. 5: Effect of initial concentration on lead removal by Rice husk 


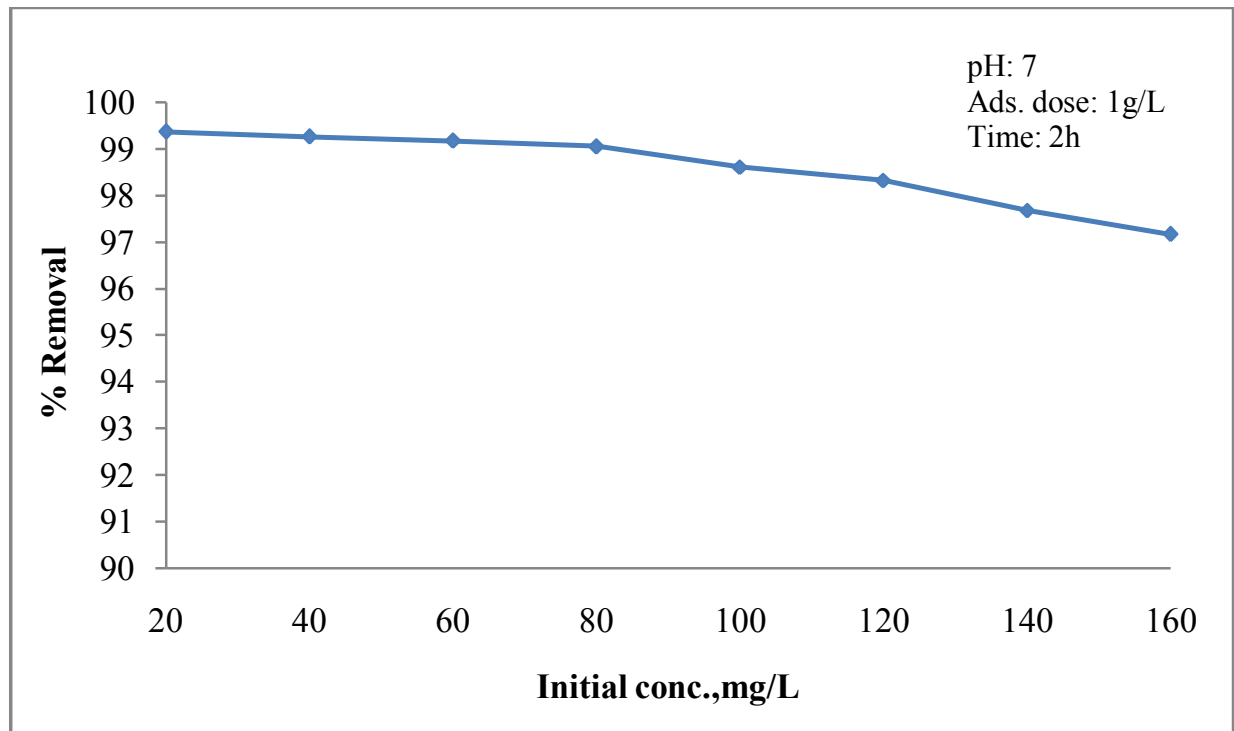

Fig. 6: Effect of initial concentration on lead removal by Groundnut shell

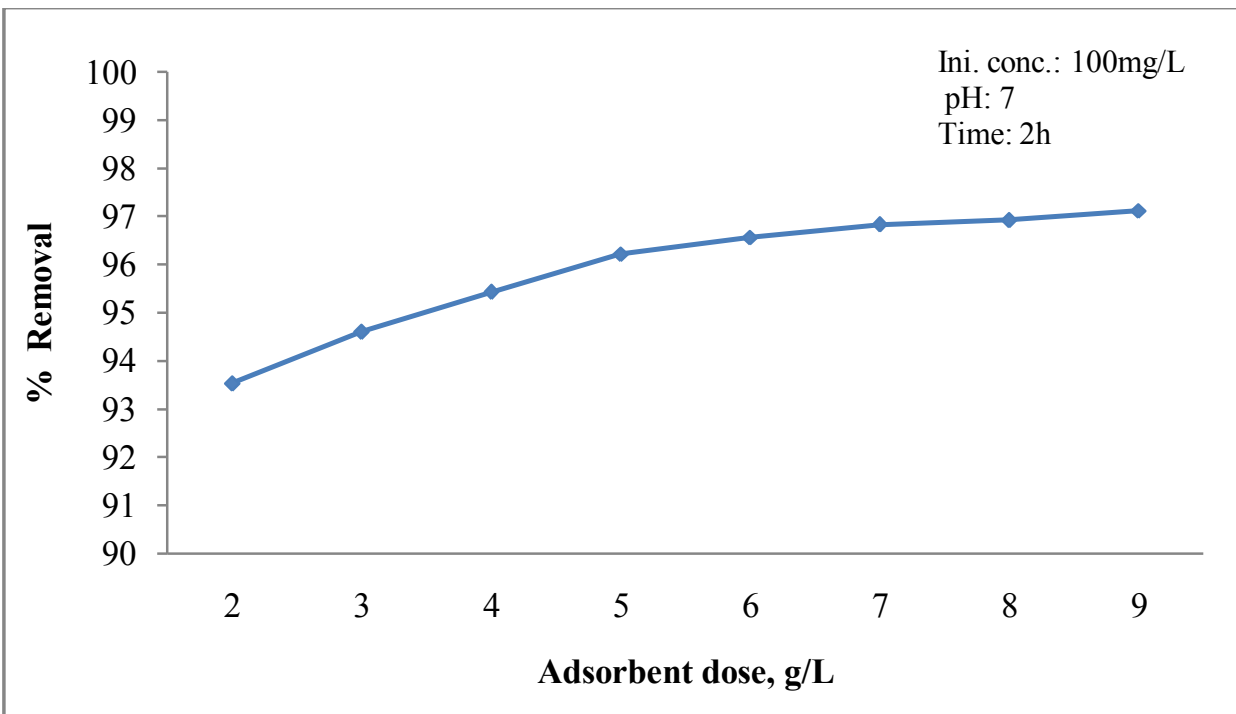

Fig.7: Effect of adsorbent dose on lead removal by Rice husk

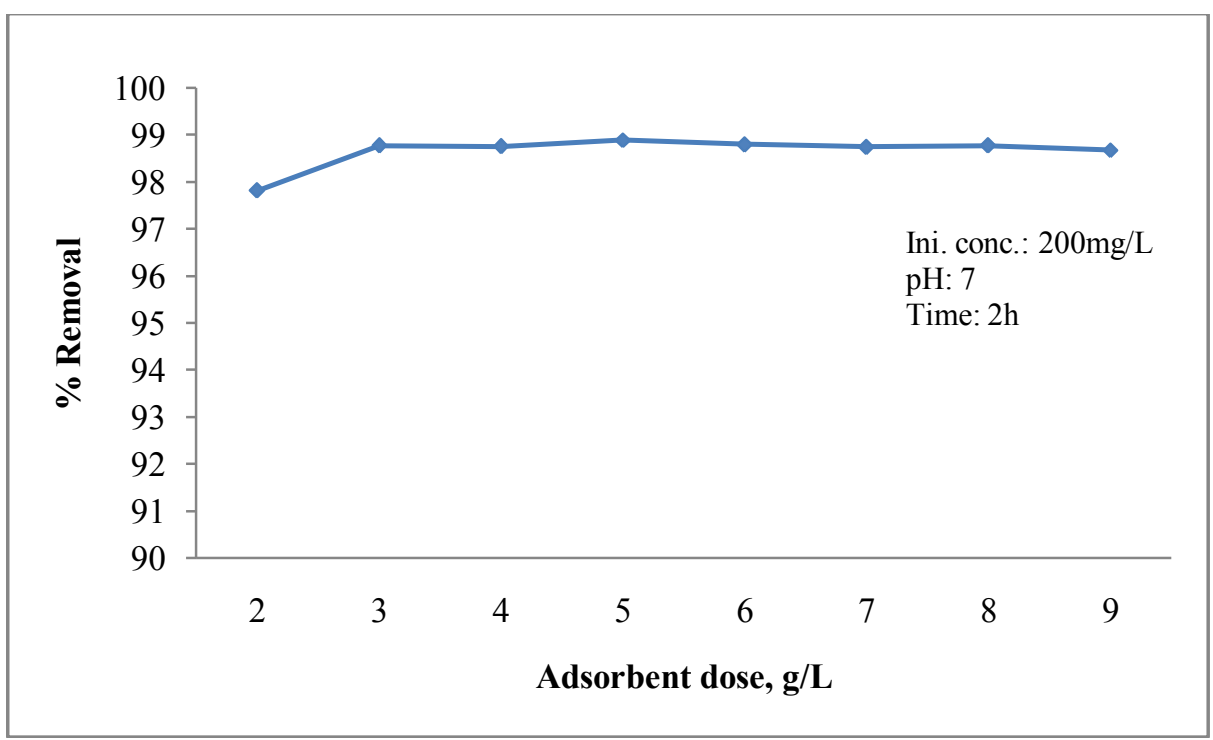

Fig. 8: Effect of adsorbent dose on lead removal by Groundnut shell 


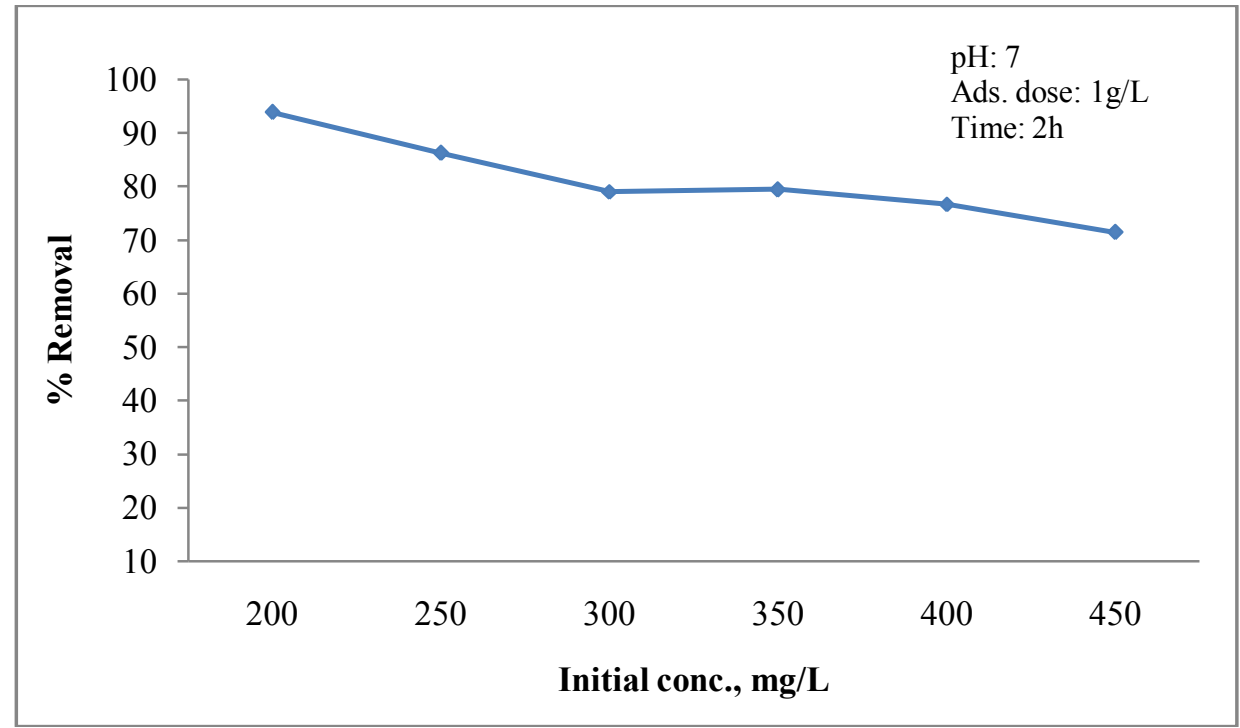

Fig. 9: Effect of initial concentration on lead removal by combined adsorbents

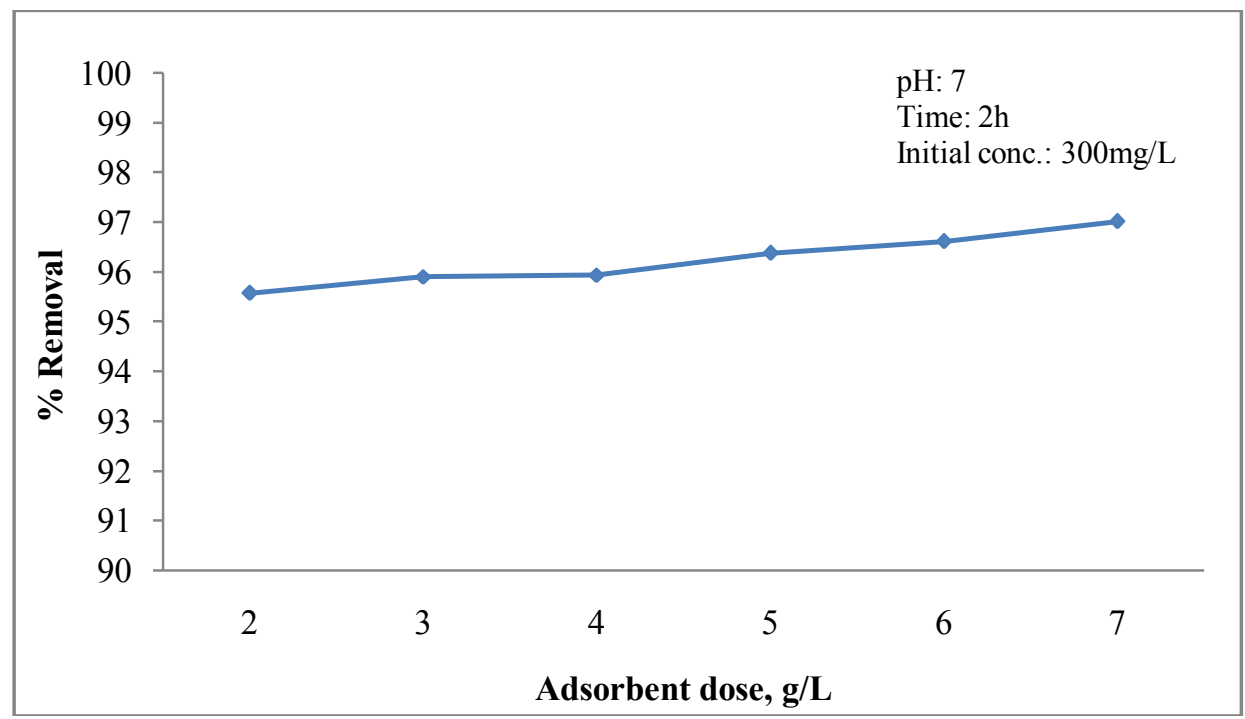

Fig. 10: Effect of adsorbent dose on lead removal by combined adsorbents

\subsection{Kinetic Modeling}

In order to investigate the biosorption kinetics, the Lagergren first order (Lagergren, 1898) and pseudo second order kinetics models were applied.

$\mathrm{dq}_{\mathrm{t}} / \mathrm{dt}=\mathrm{k}_{1}\left(\mathrm{q}_{\mathrm{e}}-\mathrm{q}_{\mathrm{t}}\right)$

This equation can be integrated to yield a linearized form as

Where,

$$
\log \left(\mathrm{q}_{\mathrm{e}}-\mathrm{q}_{\mathrm{t}}\right)=\log \mathrm{q}_{\mathrm{e}}-\mathrm{k}_{1} \mathrm{t} / 2.303
$$

$\mathrm{k}_{1}=$ Lagergren rate constant for adsorption $\left(\mathrm{min}^{-1}\right)$

$\mathrm{q}_{\mathrm{e}}=$ amount of metal biosorbed at equilibrium $\left(\mathrm{mg} \mathrm{g}^{-1}\right)$

$\mathrm{q}_{\mathrm{t}}=$ amount of metal biosorbed $\left(\mathrm{mg} \mathrm{g}^{-1}\right)$ at any time $\mathrm{t}$.

The values of $\mathrm{k}_{1}$ and qe were determined from the slope and intercept of lines in Figure.

The equation of pseudo second order model is:

$$
\mathrm{dq}_{\mathrm{t}} / \mathrm{dt}=\mathrm{k}_{2}\left(\mathrm{q}_{\mathrm{e}}-\mathrm{q}_{\mathrm{t}}\right)^{2}
$$

Integration and rearrangement of the above equation yielded the following equation 
$\mathrm{t} / \mathrm{q}_{\mathrm{t}}=1 / \mathrm{k}_{2} \mathrm{q}_{\mathrm{e}}^{2}+1 / \mathrm{q}_{\mathrm{e}} \mathrm{t}$

Where,

$\mathrm{k}_{2}=$ equilibrium rate constant of second order kinetics model $\left(\mathrm{g} \mathrm{mg}^{-1} \mathrm{~min}^{-1}\right)$

$\mathrm{q}_{\mathrm{e}}=$ the equilibrium capacity

$\mathrm{q}_{\mathrm{t}}=$ the biosorption capacity at any time $\mathrm{t}$.

In the present study these are plotted in Fig.11, Fig.12, Fig.13 and Fig.14 for Rice husk and Groundnut shell respectively. The data from the table indicates that the adsorption of lead by Rice husk and Groundnut shell are of second order reaction.

Table 1: The first order and second order sorption rate constants

\begin{tabular}{|c|c|c|c|c|c|c|c|}
\hline \multirow{2}{*}{ Adsorbent } & \multicolumn{3}{|c|}{ Pseudo first order } & \multicolumn{3}{|c|}{ Pseudo second order } & \multirow{2}{*}{$\begin{array}{l}\text { Experimental } \\
\mathrm{q}_{\mathrm{e}}(\mathrm{mg} / \mathrm{g})\end{array}$} \\
\hline & $\begin{array}{c}\mathrm{K}_{1} \\
(\mathrm{~g} / \mathrm{mg} \text { min })\end{array}$ & $\begin{array}{c}\mathrm{q}_{\mathrm{e}} \\
(\mathrm{mg} / \mathrm{g})\end{array}$ & $\overline{\mathbf{R}^{2}}$ & $\begin{array}{c}K_{2} \\
(g / m g \\
\text { min) }\end{array}$ & $\begin{array}{c}\mathrm{q}_{\mathrm{e}} \\
(\mathrm{mg} / \mathrm{g})\end{array}$ & $\mathbf{R}^{2}$ & \\
\hline Rice husk & 1.028 & 0.014 & 0.867 & 0.242 & 0.413 & 1 & 2.8014 \\
\hline Groundnut shell & 1.034 & 0.004 & 0.759 & 0.275 & 0.341 & 0.99 & 2.8953 \\
\hline
\end{tabular}

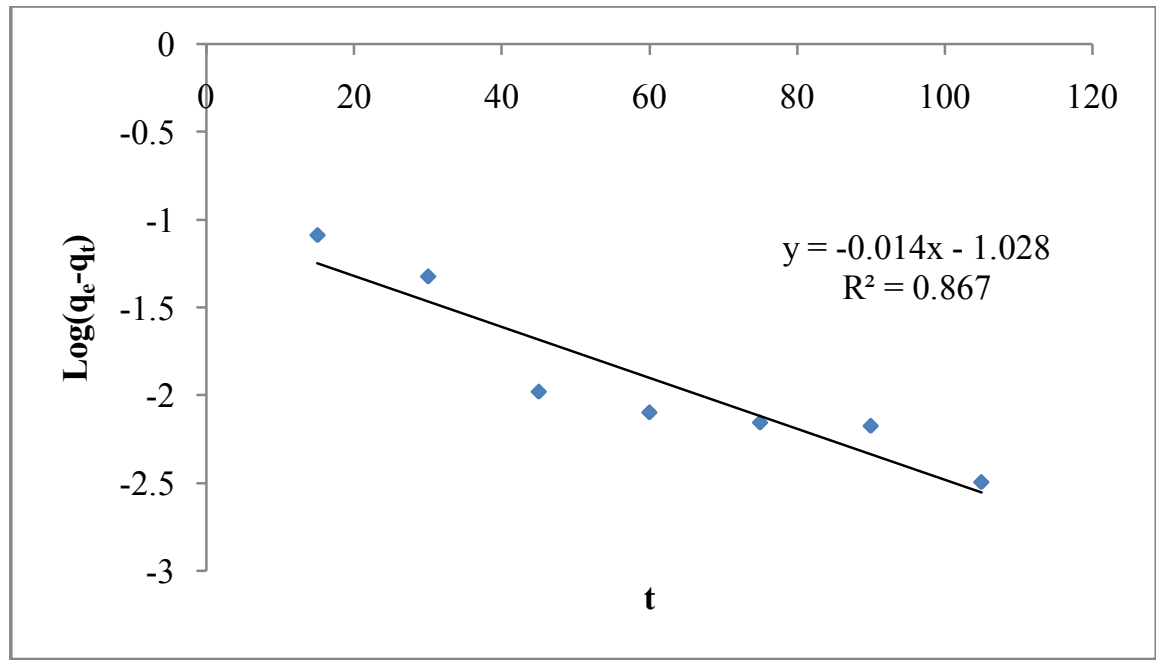

Fig. 11: Pseudo first order plot for lead on to Rice husk

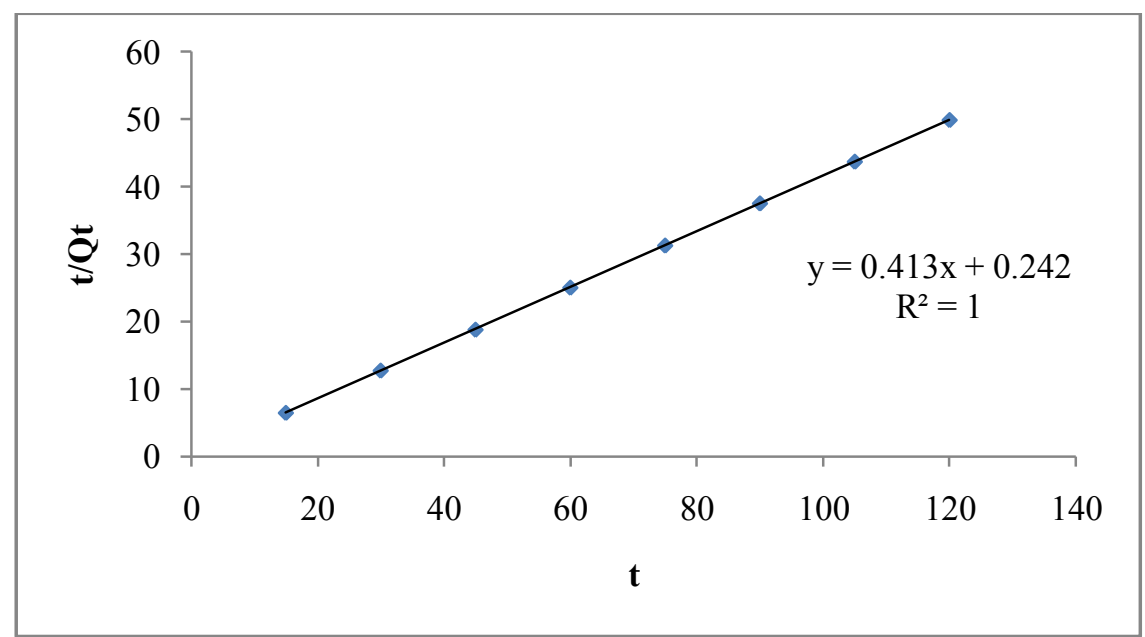

Fig. 12: Pseudo second order plot for lead on to Rice husk 


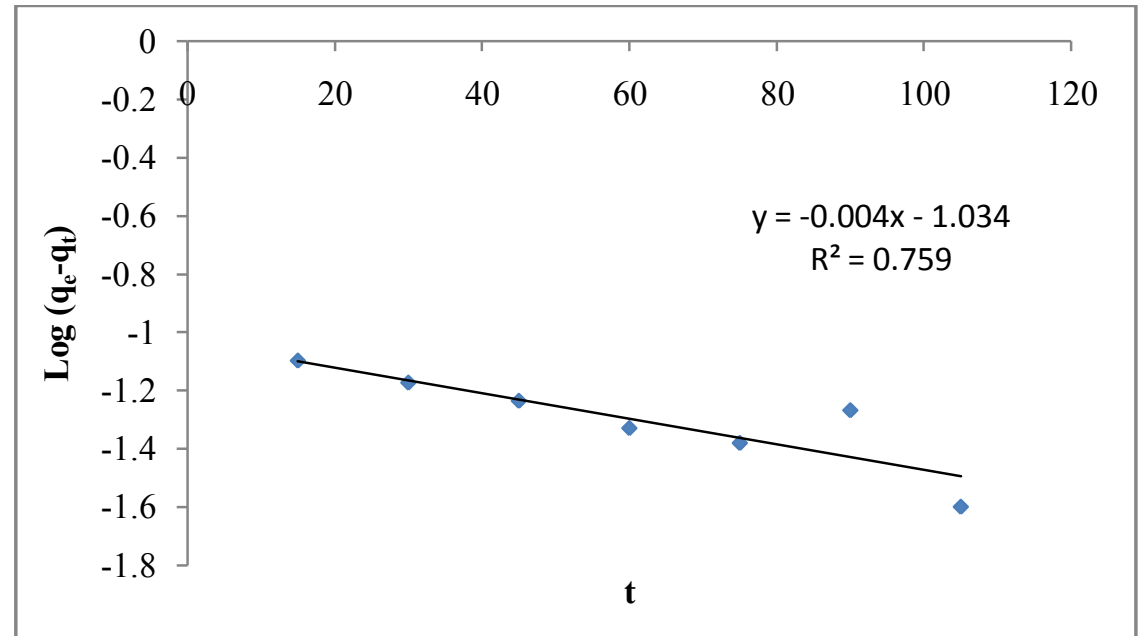

Fig. 13: Pseudo first order plot for lead on to Groundnut shell

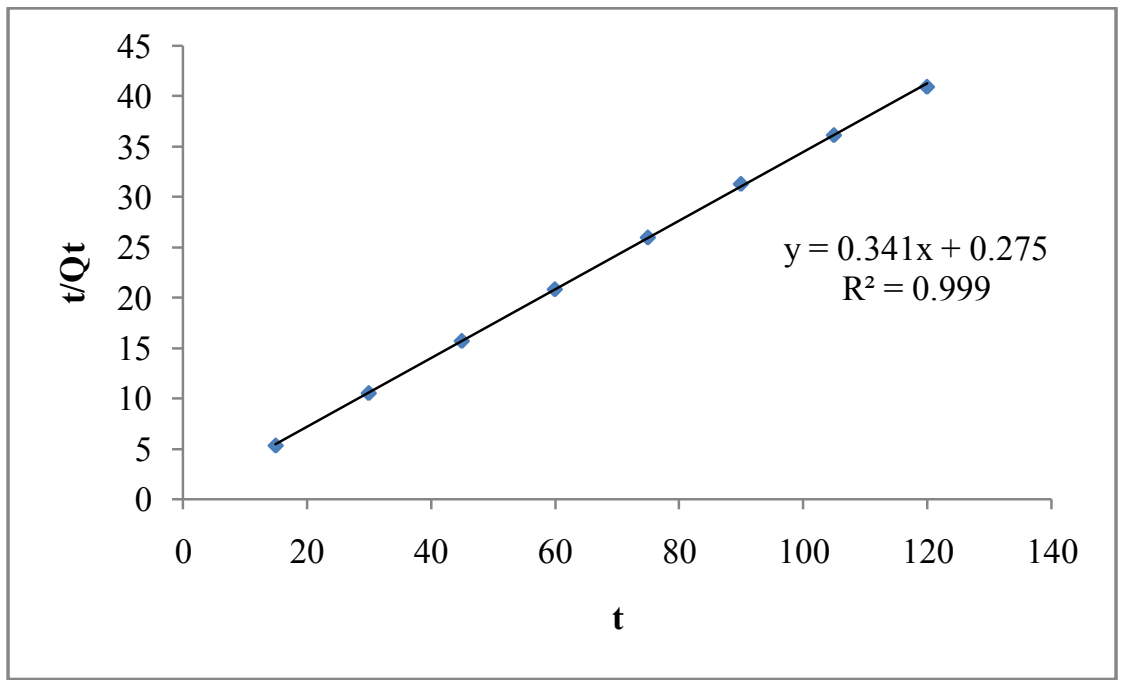

Fig. 14: Pseudo second order plot for lead on to Groundnut shell

\section{Conclusions}

Batch experiments were conducted to know the potentiality of Rice husk and Groundnut shell as adsorbents for the removal of heavy metal (lead) from synthetic wastewater. Based on the results and discussions the following conclusions can be made.

- The maximum removal efficiency of lead using Rice husk and Groundnut shell as adsorbents was obtained at $\mathrm{pH} 6$ and $\mathrm{pH} 5$ respectively.

- The contact time necessary for maximum adsorption was found to be $2 \mathrm{hrs}$.

- Effects of adsorbent on the removal of lead depend upon the initial concentration of metal ions. $9 \mathrm{~g}$ of Rice husk was able to remove $97.11 \%$ of lead conc. of $100 \mathrm{mg} / \mathrm{L}, 3 \mathrm{~g}$ of Groundnut shell was able to remove $98.67 \%$ of lead concentration of $200 \mathrm{mg} / \mathrm{L}$ and $7 \mathrm{~g}$ of combined adsorbents was able to remove $97.02 \%$ of $300 \mathrm{mg} / \mathrm{L}$ lead concentration.

- These results showed that the percentage removal of lead metal ions was high using Groundnut shell compared to Rice husk and combined adsorbents.

- From the kinetic study models plotted for the obtained results showed that the adsorption of lead by Rice husk and Groundnut shell are of second order reaction.

- As low cost adsorbents Rice husk and Groundnut shell can be efficiently used for removal of heavy metals without giving any chemical treatment for adsorbents.

\section{Suggestions For Further Research}

On the basis of knowledge gained from the present study, the following suggestions have been made for future work.

- Using same adsorbents, other heavy metal removal studies can be made. 
- Batch adsorption can be carried out for various particle size and temperature.

- Adsorption experiments can be carried out by different percentage combination of Rice husk and Groundnut shell to know the removal efficiency of heavy metals.

\section{References}

[1] O. E. A. Salam, N. A. Reiad, M. M. ElShafei, A study of the removal characteristics of heavy metals from wastewater by low-cost adsorbents, Journal of Advanced Research, 2, 2011, 297-303.

[2] A.O. Dada, J. O. Ojediran, and A. P. Olalekan, Sorption of $\mathrm{Pb}^{2+}$ from Aqueous Solution unto Modified Rice Husk: Isotherms Studies, Journal of Advances in Physical Chemistry, 2013, 2013, 1-6.

[3] Suleman Qaiser, Anwar R. Saleemi, Muhammad Umar, Biosorption of lead (II) and chromium(VI) on groundnut hull: Equilibrium, kinetics and thermodynamics study, Electronic Journal of Biotechnology, 12(4), 2009, 1-17.

[4] S. Mohan, G. Sreelakshmi, Fixed bed column study for heavy metal removal using phosphate treated rice husk, Journal of Hazardous Materials, 153, 2008, 75-82.

[5] U. Kumar, M. Bandyopadhyay, Sorption of cadmium from aqueous solution using pretreated rice husk, Journal of Bioresource Technology, 97, 2006, 104-109.

[6] Q. Li, J. Zhai, W. Zhang, M. Wang and J. Zhou, A Study on adsorption of Pb (II), Cr (III) and Cu (II) from aqueous solution by Peanut husk, Bull. Chem. Soc. Ethiop., 22(1), 2008, 19-26.

[7] B.M. Kiran, S.Srikantaswamy, H.V. Pallavi, V. Manoj, T. Tasneem, A Study on Utilization of Groundnut Shell as Biosorbant for Heavymetals Removal, Journal of Environmental Science, Computer Science and Engineering \& Technology, 2, 2012,173-186.

[8] Nhapi, N. Banadda, R. Murenzi, C.B Sekomo, U.G Wali, Removal of Heavy Metals from Industrial Wastewater Using RiceHusks, The Open Environmental Engineering Journal, 4,2011, 170-180.

[9] M. N. Abbas, F. S. Abbas, Utilization of Iraqi Rice Husk in the Removal of Heavy Metals from Wastewater, Research Journal of Environmental and Earth Sciences, 5 (7), 2013, 370-380.

[10] Samir, Sophie, Ibrahim, Kinetic study and modeling of heavy metals removal by adsorption onto peanut husks incinerated residues, Journal of Energy Procedia, 6, 2011, 143-152. 